\title{
Increased Bioavailability of Tacrolimus after Rectal Administration in Rats
}

\author{
Masayuki SakaI, ${ }^{a}$ Norio Hobara, ${ }^{a}$ Nobuo Hokama, ${ }^{a}$ Hiromasa Kameya, ${ }^{a}$ Susumu Ohshiro, ${ }^{a}$ \\ Matao SAKANASHI, ${ }^{b}$ and Hiroshi SAITOH ${ }^{*, c}$ \\ ${ }^{a}$ Department of Hospital Pharmacy, Faculty of Medicine, University of the Ryukyus; 207 Aza Uehara, Nishihara-cho, \\ Nakagami-gun, Okinawa 903-0215, Japan: ${ }^{b}$ Department of Pharmacology, School of Medicine, Faculty of Medicine, \\ University of the Ryukyus; 207 Aza Uehara, Nishihara-cho, Nakagami-gun, Okinawa 903-0215, Japan: and ${ }^{c}$ Department \\ of Pharmaceutics, Faculty of Pharmaceutical Sciences, Health Sciences University of Hokkaido; 1757 Kanazawa, Ishikari- \\ Tobetsu, Hokkaido 061-0293, Japan. $\quad$ Received March 30, 2004; accepted June 18, 2004; published online June 25, 2004
}

\begin{abstract}
The oral bioavailability of tacrolimus is low and varies considerably in humans due to first-pass metabolism by cytochrome P450 (CYP) 3A4 and the active efflux mediated by P-glycoprotein. This study was undertaken to elucidate the usefulness of rectal administration of tacrolimus as an alternative route to improve its bioavailability. Tacrolimus powder was suspended in a suppository base (witepsol $\mathbf{H - 1 5}$ ) and the tacrolimus suppository was inserted into the anus of the rats. For comparison, tacrolimus was suspended in $0.5 \%$ sodium methylcellulose solution and administered orally to rats. The dose of tacrolimus was fixed to $2 \mathrm{mg} / \mathrm{kg}$. Blood samples were collected periodically up to $24 \mathrm{~h}$ after dosing, and tacrolimus concentrations were assayed by microparticle enzyme immunoassay. The whole blood concentrations of tacrolimus after rectal administration were much greater than those after oral administration. The $C_{\max }$ and $A U C_{0-24 \mathrm{~h}}$ values after rectal administration were 3.9- and 6.9-fold greater than those after oral administration, respectively. These results clearly suggest a possibility that rectal administration of tacrolimus is capable of improving its bioavailability and cutting the costs of tacrolimus treatment.
\end{abstract}

Key words tacrolimus; rectal administration; bioavailability; blood concentration; first-pass metabolism

Tacrolimus has been widely used to prevent allograft rejection after organ transplantation. The oral bioavailability of tacrolimus widely ranges from 4 to $89 \%$ with an average of around $25 \%$ in transplant recipients. ${ }^{1)}$ Because this potent immunosuppressive agent is considered as a substrate for both cytochrome P450 (CYP) 3A and P-glycoprotein, ${ }^{2,3}$ its low bioavailability has been considered due to first-pass metabolism and active efflux in the intestine. To compensate for the low oral bioavailability, a relatively high dose of tacrolimus is administered to the transplant recipients. Because tacrolimus is an expensive drug, long-term treatment with tacrolimus puts a great strain on the patient's finances. Thus, several attempts have been done to improve its oral bioavailability, for example, by utilizing drug interaction to suppress the activities of CYP3A and/or P-glycoprotein., ${ }^{4,5}$

Rectal drug administration has several advantages over oral administration. Although the superior vein, perfusing the upper part of the rectum, drains into the portal vein and subsequently into the liver, the middle and inferior rectal veins do not drain into the portal vein. Accordingly, drugs absorbed in the lower parts of the rectum will be delivered to the systemic circulation directly, avoiding the hepatic firstpass metabolism. ${ }^{6}$ (Moreover, the expression of mucosal drug-metabolizing enzymes is much lower in the colon than in the duodenum and jejunum. ${ }^{7)}$ There is a report describing that the intracolonic instillation of nifedipine, a substrate of CYP3A, to rats attained almost $100 \%$ of the bioavailability, compared with $45-58 \%$ after oral administration. ${ }^{8)}$ It has been shown that first-pass metabolism of nifedipine took place in the small intestine rather than in the liver. ${ }^{8)}$ Therefore, it appears that the intracolonic instillation of nifedipine is capable of avoiding the substantial first-pass elimination in the intestine. Also, recent many studies have demonstrated that CYP3A-mediated tacrolimus disposition is extensive in the intestine. ${ }^{9)}$ Thus, there is a possibility that the bioavailability of tacrolimus could be improved by rectal administration. However, little information has been reported on the usefulness of rectal administration of tacrolimus. In this study, tacrolimus was administered as a suppository to rats and its blood concentrations were compared with those after oral administration.

\section{MATERIALS AND METHODS}

Materials Tacrolimus powder $(200 \mathrm{mg} / \mathrm{g})$ was kindly supplied by Fujisawa Pharmaceutical Co. (Osaka, Japan). Witepsol H-15 was obtained from Maruishi Pharmaceutical Co. (Osaka, Japan). All other reagents were of the highest purity commercially available.

Preparation of Tacrolimus Suppository One hundred milligrams of tacrolimus powder $(200 \mathrm{mg} / \mathrm{g})$ was suspended in $4.6 \mathrm{~g}$ of witepsol H-15 that had been melted by warming in a water-bath. The mixture was poured into plastic tubes (i.d., $6 \mathrm{~mm}$; length, $20 \mathrm{~cm}$ ) and allowed to stand at an ambient temperature until congealed, then stored in a refrigerator until use. The content of tacrolimus was $2 \mathrm{mg}$ per $1 \mathrm{~cm}$ suppository.

Rectal and Oral Administration of Tacrolimus to Rats Animal experiments were performed according to the Principles of Laboratory Animal Care in University of the Ryukyus. Male Sprague-Dawley rats weighing ca. $500 \mathrm{~g}$ were housed in a temperature $\left(24 \pm 1^{\circ} \mathrm{C}\right)$ and humidity $(55 \pm 15 \%)$-controlled room with a 12 -h light/dark cycle (lit. from 8:00 a.m. to 8:00 p.m.), and given free access to food (CE-2, CLEA Japan Inc., Tokyo, Japan) and water. Rats were fasted from 7:00 p.m. on the day before the experiment. In 
the early morning, a tacrolimus suppository was inserted into the anus of the rat at a dose of $2 \mathrm{mg} / \mathrm{kg}$ under ether anesthesia and the anus was closed with an adhesive, Aron Alpha (Toakasei Kogyo Co., Tokyo, Japan). For comparison, the tacrolimus powder was suspended in $0.5 \%$ sodium carboxymethylcellulose solution and administered orally to rats at a dose of $2 \mathrm{mg} / \mathrm{kg}$ using a silicone sonde. The volume of tacrolimus suspension administered was $5 \mathrm{ml} / \mathrm{kg}$. Blood samples $(50 \mu \mathrm{l})$ were periodically withdrawn from the tail vein until $24 \mathrm{~h}$ post drug administration. The whole blood concentrations of tacrolimus were determined by microparticle enzyme immunoassay (Abbott).

Pharmacokinetic and Statistical Analysis The maximal blood concentration of tacrolimus $\left(C_{\max }\right)$ and the time of its occurrence $\left(T_{\max }\right)$ were observed from each blood concentration-time profile. The area under the blood concentration-time curve $\left(A U C_{0-24 \mathrm{~h}}\right)$ was calculated by the trapezoidal rule. Statistical analysis was performed using unpaired Student's $t$-test and $p<0.05$ was considered to be significant.

\section{RESULTS}

Figure 1 shows the whole blood concentration-time curves of tacrolimus until $8 \mathrm{~h}$ after rectal and oral administration to rats. At each sampling time point, tacrolimus concentrations after rectal administration were significantly greater than those after oral administration. The blood concentrations of tacrolimus after rectal and oral administration were $25.8 \pm 4.8$ and $4.8 \pm 0.8 \mathrm{ng} / \mathrm{ml}(p<0.05)$ after $12 \mathrm{~h}$, and $20.7 \pm 5.9$ and $1.6 \pm 0.8 \mathrm{ng} / \mathrm{ml}(p<0.05)$ after $24 \mathrm{~h}$, respectively.

Pharmacokinetic parameters obtained are presented in Table 1. $C_{\max }$ and $A U C_{0-24}$ values after rectal administration were 3.9- and 6.9-fold greater than those after oral administration. $T_{\max }$ values did not significantly differ between rectal

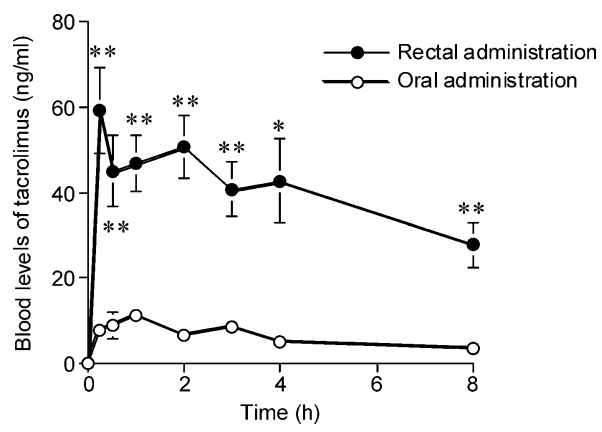

Fig. 1. Whole Blood Concentration-Time Curves of Tacrolimus after Rectal and Oral Administration to Rats

The dose of tacrolimus was $2 \mathrm{mg} / \mathrm{kg}$. Each point represents the mean \pm S.E. of five animal experiments. Some standard error bars are hidden by symbols. $* p<0.05$, $* * p<0.01$, significantly different from oral administratiion.

Table 1. Pharmacokinetic Parameters of Tacrolimus after Rectal and Oral Administration to Rats

\begin{tabular}{llll}
\hline \hline Route & $C_{\max }(\mathrm{ng} / \mathrm{ml})$ & $T_{\max }(\mathrm{h})$ & $A U C_{0-24 \mathrm{~h}}(\mathrm{ng} \cdot \mathrm{h} / \mathrm{ml})$ \\
\hline Rectal & $59.2 \pm 9.5^{*}$ & $0.3 \pm 1.8$ & $707.0 \pm 28.6^{*}$ \\
Oral & $15.0 \pm 3.4$ & $1.0 \pm 0.5$ & $103.2 \pm 6.7$
\end{tabular}

The dose of tacrolimus was $2 \mathrm{mg} / \mathrm{kg}$. Data represents the mean \pm S.E. of five anima experiments. $* p<0.001$, significantly different from oral administration. $C_{\text {mx }}$; maximal blood concentration; $T_{\max }$, time to reach $C_{\max } ; A U C_{0-24 \mathrm{~h}}$, area under the blood concentration $v s$. time curve from 0 to $24 \mathrm{~h}$. and oral administration.

\section{DISCUSSION}

Tacrolimus bioavailability after intraintestinal and intraportal administration to rats was reported to be approximately 25 and $40 \%$, respectively, indicating that intestinal and hepatic first-pass metabolism of tacrolimus was extensive. ${ }^{10)}$ Supporting these observations, tacrolimus blood concentrations were low after oral administration in this study. When tacrolimus was administered in a suppository base, blood concentrations and $A U C_{0-24 \mathrm{~h}}$ were much greater than those after oral administration, implying that rectal administration was useful for improving the bioavailability of tacrolimus.

The elimination of tacrolimus in the whole blood was slow in spite of a fact that this drug is extensively metabolized in the liver after absorption. Even at $24 \mathrm{~h}$ after rectal administration, tacrolimus was still present in the whole blood. This was as the same in the case of oral administration. Moreover, blood concentrations of tacrolimus were widely fluctuated in the case of rectal administration (Fig. 1), suggesting its erratic absorption. This preliminary study was done using a relatively higher dose of tacrolimus $(2 \mathrm{mg} / \mathrm{kg})$ compared with its clinical dose for transplant recipients. Thus, the results might be attributed to slow dissolution of tacrolimus in the limited volume of colorectal fluid.

In this study, the whole blood concentrations of tacrolimus after intravenous administration to rats were not assayed, because it was difficult to administer tacrolimus solution to rats precisely. Thus, the bioavailability after rectal administration was not evaluated here. Accordingly, the following points are still remained to be resolved: 1) how much tacrolimus absorbed could avoid the first-pass metabolism in the intestine as well as in the liver and 2) how much P-glycoprotein present in the colon is capable of interfere with the absorption of tacrolimus. Greater activity of the efflux transporter has been shown in the distal colon. ${ }^{11)}$ In order to assess these points, whole blood concentration after rectal and oral administration should be evaluated using several doses of tacrolimus in further studies. However, our present study fully suggests a possibility that the development of a rectal dosage form of tacrolimus could contribute to improve its bioavailability in transplant recipients and cut the costs of tacrolimus treatment.

Acknowledgements The authors thank Fujisawa Pharmaceutical Co. for kindly supplying tacrolimus powder.

\section{REFERENCES}

1) Venkataramanan R., Swaminathan A., Prasad T., Jain A., Zuckerman S., Warty V., McMichael J., Lever J., Burckart G., Starzl T., Clin. Pharmacokinet., 29, 404-430 (1995).

2) Shiraga T., Matsuda H., Nagase K., Iwasaki K., Noda K., Yamazaki H., Shimada T., Funae Y., Biochem. Pharmacol., 47, 727-735 (1994).

3) Wacher V. J., Silverman J. A., Zhang Y., Benet L. Z., J. Pharm. Sci., 87, 1322-1330 (1998)

4) Kramer M. R., Merin G., Rudis E., Bar I., Nesher T., Bublil M., Milgalter E., Transplant. Proc., 29, 2657 -2659 (1997).

5) Jones T. E., Morris R. G., Clin. Pharmacokinet., 41, 381-388 (2002).

6) van Hoogdalem E. J., de Boer A. G., Breimer D. D., Clin. Pharmacokinet., 21, 11-26 (1991). 
7) Shen D. D., Kunze K. L., Thummel K. E., Adv. Drug Del. Rev., 27, 99-127 (1997).

8) Grundy J. S., Eliot L. A., Foster R. T., Biopharm. Drug Dispos., 18, 509-522 (1997)

9) Doherty M. M., Charman W. N., Clin. Pharmacokinet., 41, 235-253
(2002).

10) Hashimoto Y., Sasa H., Shimomura M., Inui K., Pharm. Res., 15, 1609-1613 (1998).

11) Stephens R. H., Tanianis-Hughes J., Higgs N. B., Humphrey M., Warhurst G., J. Pharmacol. Exp. Ther, 303, 1095-1101 (2002). 